\title{
Genetic Problems Affecting Search for New Oil Regions
}

\author{
By David White, * Washington, D. C.
}

(New York Meeting, Februsry, 1920)

IN THESE days, when detailed investigations of stratigraphy, structure, and sand conditions so frequently result in the discovery of new oil fields, and applause from oil companies and the public, geologists do well to walk humbly, and punctiliously to admit that the geologic principles controlling the distribution of oil and gas have as yet been discovered only in part, and that what remains yet to be learned is probably vastly more than what is already known. The few experiments already attempted have been fragmentary, and somewhat desultory, and however positive each of us may be with respect to certain theoretical conclusions, many of the fundamental questions as to the origin and mode of occurrence of petroleum are subject to radical disagreement. Of the chemical changes attending the generation of petroleum from organic matter, little is actually known. Most of the postulated formulas are liable to be misleading, through ignorance of essential factors. Open-mindedness is therefore a prime essential at the present stage of our science. Nevertheless, adopting the hypothesis that oil originates in some manner fundamentally connected with the organic theory, and in possible departure from such open-mindedness, the writer will pay no attention to the so-called inorganic theory, since every attempt to apply this theory to the study of old oil fields, or to the discovery of new ones, affords cumulative evidence of its inadequacy.

In this paper, some of the factors affecting the occurrence of petroleum that the writer believes worthy of consideration by the prospector for oil in any new region will be discussed. Some of these, which are less generally understood, will be considered somewhat in detail. Other points, the significance of which cannot now be determined, require more field study, and for that reason are here brought to the attention of the field geologist. On the other hand, certain theoretical points which do not bear especially on the oil possibilities of a new region will be given little or no attention. The main topics that will be discussed are: (1) sufficiency of carbonaceous detritus and residues in the oil-forming rocks; (2) stage of carbonization of the organic matter in the oil-bearing formations; (3) folding of the strata; (4) thickness of sedimentary formations; (5) conditions of deposition.

* Chief Geologist, U. S. Geological Survey. 


\section{Sufficiency of Carbonaceous Debris and Residues in THE OIL-FORMING Rocks}

Most oil and gas geologists agree that in those formations in which oil is found there must be sufficient organic matter genetically to account as mother substance for the oil, which is believed to have escaped from its mother rock into some suitable and accessible reservoir rock where it is confined beneath impervious strata. However, very little seems to be known as to the requisite quantity of mother substance or as to the maximum distance at which this substance may be situated from the reservoir.

Most geologists assume that this mother substance is carbonaceous, but others hold that recognizable carbonaceous debris or visible residues are not necessarily present. "Bituminous" or other carbonaceous shales and limestones are almost invariably searched for because, seemingly with good reason, such deposits are regarded as the principal materials from which petroleum may be generated; certainly they are the rocks from which oils nearest to typical petroleum may be artificially produced by distillation. As shown by Orton and others, similar carbonaceous matter adequate for supplying oil and gas may be found in most regions disseminated through the rock or concentrated in certain layers; it is present in ample amounts even in less distinctly carbonaceous shales and limestones, and in some sandstones, and there seems no room for doubt that oil in commercial amounts has been derived from such deposits. Most dark limestones, sandstones, and shales, as well as ordinary black shales, owe their dark tones to the presence of carbonaceous residues, which are easily recognized under the microscope. Yet it remains to be seen how much of such organic matter is requisite, as a minimumprobably, in reality, an average minimum. Circumstantial evidencethe conditions actually presented in certain oil fields-seems to indicate that the carbonaceous matter need compose but a very small percentage of a supposed mother formation, if the matter is of the right sort, and if other requisite conditions are fulfilled, and that a very great thickness of the mother formation is not indispensable. In general, however, our most productive oil deposits are found in districts containing formations in which there is evidence of abundant life, with ample vegetal matter. That only smaller productions are found in districts containing little carbonaceous matter may prove to be a rule with numerous exceptions.

In the search for oil in regions containing thick series of strata so barren of carbonaceous matter as the "Red Beds" of New Mexico, Arizona, and the northern Rocky Mountain States, or as the Jurassic of Utah, southwestern Colorado, northern Arizona, and northwestern New Mexico, or as the Newark formation of the Connecticut Valley and Pennsylvania, the question as to the quantity of organic matter appears, at the vor. $2 x y,-12$. 
present moment, to be somewhat insistent. As bearing in a practical way on this problem, the demonstrated occurrence of oil in the Conemaugh of the Appalachian Basin, in the Embar and associated beds of Wyoming, in the "Red Beds" of north Texas and Oklahoma, and in small amounts in red beds near Roswell, New Mex., may be cited. It must be admitted, however, that the Conemaugh carries thin coals and carbonaceous shales; that the Permian reds of Oklahoma and Texas contain rare beds of coal and carbonaceous shales, usually of limited horizontal extent; and that disseminated carbonaceous matter, in aggregate amounts larger than at first thought, may be present in portions of the Embar and in intercalated shales or sandstones in the "Red Beds" of New Mexico. On the other hand, it is a question whether, in at least some of these cases, the oil has not migrated upward from more carbonaceous beds in relatively remote, underlying formations; or even whether the oil has not migrated downward. The presence of other oil sands lying in more richly carbonaceous formations, at different and sometimes great depths beneath the "Red Beds" sands in the Appalachian Basin and in the MidContinent field, lends weight to the supposition that in some cases the oil has migrated upward instead of originating in the "Red Beds" themselves. If the oil in the latter regions has ascended into the "Red Beds," deeper sands should be tested in the possibly less forbidding shales beneath the Embar of Wyoming and the Abo of New Mexico, and beds to the base of the Percha will be explored in southern New Mexico, if the Percha is present and not too greatly altered.

A. W. McCoy, who has had most excellent opportunities for studying the composition of the beds penetrated by the drill in the Mid-Continent field, points out ${ }^{1}$ the presence of ample carbonaceous material, including oil shale, intimately associated with the Bartlesville sand in northern Oklahoma, and suggests that closer inspection will reveal the presence of sufficient mother substance in close proximity to the oil sands in other regions. The discovery, somewhere, of oil in a series of distinctly noncarbonaceous "Red Beds," directly underlain by metamorphic rocks or igneous masses, with no possible source in nearby unaltered sediments, would have an important bearing on this problem, and should be recorded; drilling under such conditions, however, will probably be done with great hesitation. The argument that oil in the above-mentioned "Red Beds" has migrated downward suggests the inquiry whether the associated gas also gravitated. Certainly, if oil has not been generated in beds which, on casual view, appear to contain very little organic matter, the petroleum in some of our sands must have migrated across many hundred feet of strata before finding hospitable storage in its present reservoirs.

${ }^{1}$ Jnl. Geol. (1919) 27, 252. 
The term "organic matter" should be restricted to carbonaceous debris and residues, as distinguished from non-carbonaceous mineral deposits of organic origin, such as shells, diatoms, etc., which may now be devoid of any associated hydrocarbons. Such mineral deposits do not, I believe, serve as mother substance of oil, although, when porous, they may offer excellent storage. In many, perhaps most cases, however, limestones contain some matter that is strictly organic and may have been mother substance. Impure, especially argillaceous, bituminous limestones should well serve the purpose of mother rock, and have undoubtedly done so.

The question as to whether oil may not have been generated in the biochemical stage at the time of the decay and deposition of the organisms, such as mollusca or diatoms, as believed by Stuart and many other oil geologists, is a debatable point germane to this subject, but will be considered in connection with the influence of diastrophic movements. The discovery of oil pools in a great thickness of strata actually barren of carbonaceous or so-called bituminous matter, but containing limestones largely of "organic" origin, and underlain by metamorphic or igneous basements, would give force to this theory.

\section{Stage of Carbonization of the Organic Matter in the Oil-Bearing Formations}

A study of the incipient regional metamorphism of carbonaceous deposits in the coal and oil fields of the United States and other countries shows that no commercially important oil fields have yet been discovered in any area where the fuel ratios of the coals, occurring in the formations in which oil is sought or in overlying formations, exceeds 2.3. The progressive devolatilization by which the coals in any region or formation have been transformed from peats to lignites, bituminous coals, etc., and finally to graphite, is the first indication of incipient metamorphism ${ }^{2}$ of the rocks of the area. The proximate analysis of the coal or coaly deposits, as the writer has shown, ${ }^{3}$ is a sort of "ultra-violet" method of observing this initial stage of regional metamorphism of the ordinary type. Other attending criteria include the stages of dehydration, consolidation or lithification, development of jointing and cleavage, and, in due time, schistosity and mineralization.

More observations and tests are necessary to fix more exactly the stage of regional alteration beyond which commercial oil pools, though

${ }^{2}$ In this transformation the mass of organic debris (coal or coaly matter) is altered both in chemical composition and physical characters. In other words, technically, it is genuine metamorphism.

${ }^{8}$ Jnl. Wash. Acad. Sci. (1915) 6; Bull. Geol. Soc. Amer. (1917) 28, 727-734. 
formerly present, will not have survived, but it is probable that the limit falls, in general, slightly lower than the point at which coals of the ordinary bituminous type show a fuel ratio of 2.2 , or 68 per cent. of fixed carbon in the pure coal; it may approach nearer the ratio of 2.0 , or 66 per cent. fixed carbon. Coals verging toward the sapropolic type, such as are believed by many to approach more closely the typical mother substance of oil, are more fatty and accordingly richer in hydrogen and lower in fixed carbon (pure coal basis) than the other types, until, in the course of alteration by geologic processes, they approach the above limit, when the volatile matter seems to disappear rapidly. At the semibituminous stage (fuel ratio 3.0, fixed carbon 75 per cent.), their carbonization is approximately on a parity with typical bituminous coal.

It is important that, in a new region under consideration as to oil possibilities, every precaution be taken to ascertain whether the alteration of the rocks, as indicated by the stage of carbonization of the carbonaceous deposits, has not gone so far as to preclude the survival of oil in commercial amounts. As I have shown in the papers already cited, drilling in regions of greater metamorphism will find only gas or mere showings of "white oil"-approximately kerosene-generally little more than samples, and nowhere in commercial amount. This principle appears to be proved by thousands of tests in the Appalachian field, in the Mid-Continent region, and in other parts of the world.

Oil in commercial amounts should not be expected in the Devonian of east-central and southeastern New York and eastern Pennsylvania; in the Paleozoic regions of Georgia; in the Arkansas coal field; ${ }^{4}$ nor in those areas of northeastern Kentucky, of eastern Tennessee, of Alabama, of the Paleozoic region in southeastern Oklahoma, and portions of New Mexico, Colorado, Montana, Utah, and Washington, as well as of Pennsylvania, Maryland, Virginia and West Virginia, where the regional carbonization has passed the stated limit. The Utica, Genessee, Hudson, Ohio, Chattanooga, and Woodford shales are splendid depositories of mother substance, but it is futile to search for oil in the associated "sands" in regions where the organic matter of these shales is too far altered.

It is unfortunate that so little attention has been given to this factor of control of the distribution of oil, and so little systematic effort has been made to secure such evidence as might have been gained. Data are needed, for example, as to the carbonization of the organic matter in the

4 Over 300 holes have been drilled in the Arkansas coal field with but a showing of "white oil" in a single instance, although, as in Pennsylvania, West Virginia and other areas, gas may be present in commercial amounts in anticlines, where the carbonization has progressed too far for the survival of oil pools. An asphaitic dyke at Mena, in the altered region of Arkansas, has been anthracitized. 
Percha (Devonian) shale and the Magdalena limestone and Sandia formations in portions of New Mexico, ${ }^{5}$ for the information concerns not only the probability of finding oil pools in or adjacent to these formations, but also the problem as to the source of oil that may be found in the overlying Red Beds. It is known that the coals of the Mesa Verde, in portions of the Trinidad, Crested Buttes, and Durango coal fields, approach, if they do not pass, the fuel-ratio limit, but the boundaries of the areas in which oil should not be expected in this or the underlying formations have not been determined for lack of sufficient and properly distributed coal analyses. The high probability that the abundant organic debris in formations like the Mancos and Graneros, and the still older formations beneath the Mesa Verde, have been still more altered must not be overlooked in any search for oil deep below the coals in these regions of relatively high carbonization.

Also, in the lower Saline River Valley, in southeastern Illinois, where the carbonization advancing toward the south approaches the oil limit, some uncertainty will attend exploration for oil in anticlines of the Mississippian, Devonian, and Trenton, which furnish oil in other parts of the state. The degree of carbonization of organic deposits in the exposed beds, and the probably greater alteration of the underlying beds, deserve further consideration, wherever the data are procurable, in the regions of some of the anticlines located in the direction (southwest) of advancing carbonization in Montana; and it should not be ignored in the vicinities of the coal fields near Sunnyside, Utah, and in Washington and Oregon.

Disregarding contact metamorphism, which from the present standpoint is unimportant, it is probable that regional alteration in much of the Newark formation of the Atlantic States has advanced too far to encourage the driller, even where the series has great thickness, contains ample carbonaceous matter, and is not too closely folded. If found to be not too far altered, it should, where sufficiently thick, be reviewed by the oil geologist. Reliable information, if it can practicably be obtained, is to be desired, as to the stage of alteration of the Upper Paleozoic in portions of Montana, Utah, and Arizona, though it is possible that in some areas inferences based only on cleavage, induration, incipient schistosity, and mineralization (not contact alteration), can be drawn. In many instances, valuable deductions may be based on distillation tests of oil shales or other richly bituminous shales which, if far devolatilized, will yield little oil, though containing much carbon.

In passing, it should be noted that: $(a)$ local, slight variations of carbonization are not to be ignored, for they are to be expected, especially

s The coal of the lower Pennsylvanian appears to be too far altered in the Pecos Valley, about 10 miles above New Pecos, and samples from Bernalillo County cast suspicion on the same formation in that county. 
in closely folded and faulted areas; $(b)$ in general, carbonization advances downward, according to the law of Hilt, ${ }^{8}$ so that the fuel ratios of coals in underlying formations will, in most cases, be higher than in the exposed formations, thus offering no hope of getting oil at greater depths where the regional alteration of the exposed rocks is too great; $(c)$ the carbonization rule applies only to areas in which the alteration is regional, not contact metamorphism; $(d)$ the fuel ratios are typically based on coals or coaly deposits of the so-called bituminous group, and may be satisfactorily determined in coaly streaks, in very earthy and bony coals, and in shales containing great amounts of organic matter, though it is not yet proved that they can be determined in shales carrying but small percentages of carbonaceous matter. Attempts to determine the pcrcentage of fixed carbon in the organic matter of ordinary carbonaceous shales have not yet been wholly successful, but experiments are now in progress with the object of learning the minimum of carbonaceous matter that may be reliably subjected to proximate analysis in the average carbonaceous shale. If methods can be devised for successfully ascertaining the fuel ratio in the organic matter of even moderately carbonaceous shales, criteria of the greatest value will be available to the driller.

As bearing upon the grade of oil that may be expected in a new region, attention may again be called to the observation that, in general, the oils in regions of relatively high, but not too high, carbonization are characteristically of the highest grade, that is, of low gravity; while in regions of less carbonization the oils average higher in gravity. Going still further, as the writer has elsewhere pointed out, the oils found in regions of low-rank coals, such as lignites (brown coals), are also characteristically, though not without exception, lowest in rank, notwithstanding the lack of satisfactory explanation of the fact, on what may at the present moment be considered a reasonable chemical basis. The true explanation may come from the thorough application of experimental physics and physical chemistry to the oil problem.

The causes of carbonization (alteration) of the organic debris and residues in sedimentary formations have been more fully discussed in my previous papers, but will be briefly reviewed in the following section.

\section{Folding of Strata}

Folding of the strata, or the development of structure, is almost universally regarded as an essential feature of any oil region. The migration and "gravitational" segregation of oil, gas, and water are commonly supposed to be connected with the existence, if not indeed with the origin, of folds, and in particular with minor local

${ }^{8}$ U. S. Bureau of Mines Bull. 38 (1913), 125. 
-anticlines and domes. Therefore, folding is always looked for and analyzed in detail.

However, to what extent and through what processes folding operates as a cause, or a means, or, on the other hand, whether it is to be regarded only as an effect or a mere indication, is yet to be shown. Most of us hold that folds facilitate the segregation and localize the distribution of oil and gas pools, ${ }^{7}$ and are therefore of great consequence in the search for new oil fields; contrasted with this view, folding seems to be regarded by some geologists mainly as an effect of questionable importance.

One of the most thoughtful advocates of the operation of folding as a cause of the migration of oil and gas is Marcel R. Daly, ${ }^{8}$ who starts with the assumption that the oil already exists, presumably from the date of deposition of the terrane, disseminated in the clays, sands, etc. in the form of minute spherical globules between the mineral particles. Under increasing loading by deposition of superincumbent strata, the argillaceous and organic deposits are compressed and the water, oil, and gas are gradually squeezed out of the compacting deposits, moving in the direction of least resistance into the less compressible sandy beds and sandstones. Coalescence of the globules and concentration of the liquids proceed en route. In the sandstone, separation of the water, oil, and gas tend to go forward according to the size of the pore spaces, the water, with its greater capillary tension, tending to occupy the fine-grained portions and forcing the oil and gas into the larger voids. Horizontal stresses of diastrophism, causing new and greater differential compression of the beds, produce waves of unequal compression and, overcoming friction, drive the water and hydrocarbons into the zones of less pressure, some of which are the forerunners of anticlines as buckling proceeds, the tops of the anticlines offering zones of least compression, while the bottoms of the synclines are most squeezed.

The important point of Daly's presentation is the function of loading and thrust pressure in causing the escape of the water and oil from its matrix into the sands, and in overcoming capillary resistance to further migration into reservoirs and anticlines. It is hoped that this paper will bring partial support to some of Mr. Daly's conclusions.

In previous discussions ${ }^{\theta}$ of the features common to the genesis of coal and of oil, the writer has insistently pointed out that the evolution of each is brought about through the common agency of dynamic forces-mainly horizontal stresses-acting on loaded strata and causing the progressive

7 Preliminary compilations by K. C. Heald indicate that over 88 per cent. of the anticlines and domes in the Osage Nation are oil-bearing, as compared with about 15 per cent. of the synclines.

s Trans. (1916) 56, 733-753.

- Jnl. Wash. Acad. Sci. (1915) 6; U. S. Bureau of Mines Bull. 38 (1913) 91; Bull. Geol. Soc. Amer. (1917) 28, 727. 
devolatilization of the organic debris and residual products buried in the sedimentary deposits. Both coal and oil are products of alteration, by geologic processes, of organic matter not only similar, but, at least, in part, identical in composition. Coal consists of the mass or stratum of relatively pure organic debris, including the residual solid hydrocarbons left in the process of transformation from peat, or its genetic equivalent (deposited under different conditions), to graphite. Oil, on the other hand, is a volatile product of this natural "distillation" by the same agencies, of the organic debris and residues buried in the sedimentary deposits.

The transformations or geochemical changes are intimately associated with, if they are not actually caused by mainly horizontal stresses, under loading, with consequent molecular displacement, and some incidentally generated heat. The temperature developed during the process was probably very moderate, and almost certainly was not great enough to distil the organic matter at slight pressures. ${ }^{10}$ There is generally but little trace of alteration of the rock except progressive dehydration, compression, and lithification in the earlier stages, with some sericitization; the latter can, however, hardly be attributed to hydrothermal action, ${ }^{11}$ since there is no evidence of the percolation of magmatic waters. Deformation of crystals has not yet been observed, except in sands of regions where the carbonization is approaching anthracitization, in which case a change to quartzite, and some deformation of quartz grains, may be noted, as well as occasional thin platy cleavage, probably representing incipient schistosity. As the regional alteration approaches the graphitic stage, mineralization and considerable deformation of the rock grains, including pebbles, may locally be noted. In short, the transformation of the organic debris and the concomitant changes in the surrounding rock are such as are characteristic of the earliest phase of normal regional metamorphism. The chemical reactions in the organic matter are not yet convincingly explained. The processes are now in operation, though they are more energetic and efficient in regions and during periods of diastrophic movement.

Experimental evidence strongly, but not conclusively, supporting

${ }^{10}$ Observations by C. E. Van Orstrand, of the UT. S. Geol. Survey, of teinperatures in several deep wells in the Northern Appalachian region indicate temperatures, at the present time, of approximately $170^{\circ} \mathrm{F}$. $\left(77^{\circ} \mathrm{C}\right.$.) at depths of $7500 \mathrm{ft} .(2286 \mathrm{~m}$.), the increase averaging 1 to $50 \mathrm{ft}$. in depth. [See Ohio Gas \& Oil Men's Jnl. (Sept., 1919) 1,22.] The temperature gradient is found to be steeper in other regions. Thus, at a depth of $3000 \mathrm{ft}$. $\left(914 \mathrm{~m}\right.$.) at Newkirk, Okla., it is $128.1^{\circ} \mathrm{F} .\left(53.5^{\circ} \mathrm{C}\right.$.) or $1^{\circ} \mathrm{F}$. per $46 \mathrm{ft}$, while in the Ranger, Tex., field, at $3000 \mathrm{ft}$. the temperature was $134.9^{\circ} \mathrm{F}$. $\left(57.1^{\circ} \mathrm{C}\right.$.), the rate of increase being $1^{\circ}$ to $45 \mathrm{ft}$. No doubt very much steeper gradients will be found in regions of more recent movement.

"Studies of the petrology of oil sands are now in progress by M.' I. Goldman, of the U. S. Geol. Survey. 
the pressure theory of the origin of oil has recently been adduced ${ }^{12}$ by Alex. W. McCoy, geologist of the Empire Gas and Fuel Co. By means of pressure on the ends of a cylinder of oil shale enclosed in a tube, the walls of which were thinner in the central zone than at the ends, so as to allow bulging, Mr. McCoy was able to induce flowage in the oil shale, and, without causing an appreciable amount of heat, developed small globules of oil in the shale which were visible with a hand lens. The material used in the experiment was typical oil shale, capable of yielding 25 gal. (94.6 l.) of oil to the ton, and having a crushing strength of about $3000 \mathrm{lb}$. per sq. in. $(211 \mathrm{~kg}$. per sq. cm.). No oil could be removed by solvents prior to the experiment. From this and other experiments, Mr. McCoy concludes: (1) that the solid bituminous material in the rocks is only changed to petroleum by pressure in local areas of differential movement ; (2) that "the accumulation of oil into commercial pools is accomplished by capillary water; and this interchange only takes place in local areas where the oil-soaked shale is in direct contact with the water of the reservoir rock," such conditions being explainable either by joints or faults; (3) that "some adjustment takes place" until the oil in the sand has found the larger openings, where it remains indefinitely; (4) that "the amount of oil in any field could have been derived from normal bituminous shales in close proximity to the pay horizon;" (5) that areas of maximum differential movement are in accord with anticlinal structures, that the maximum sub-surface faulting is on the flanks and sides of the anticlines, and that the best production runs in trends parallel to the faulted zone. The most important part of Mr. McCoy's experiments, as it seems to me, is the production of petroleum by pressure alone acting on unaltered shale.

As noted in my discussions of coal, regional carbonization results from the progressive devolatilization of carbonaceous matter in the strata on a regional scale under dynamic stresses, dominantly horizontal thrusts, probably with development of moderate temperatures. It is most advanced in the regions of apparently greatest thrust compressions and hence of greatest molecular displacement; and in any region it is seen to be greatest on the side of greatest cumulative and sustained horizontal stresses.

With reference to both carbonization and folding, it is important for a field geologist, prospecting for oil in new regions, to remember that folds are likely to mark lines of pre-existent weakness resulting from former anticlinal buckling or faulting in the deeper strata, or that they may occur in zones of less competence, such, for example, as along zones of marked or abrupt unconformities; also that buckling and, in particular, overthrusts are the structural changes (really strains) that compensate and relieve

12 Notes on Principles of Oil Accumulation: Jnl. Geol. (1919) 27, 252-262. 
the pressure stresses and tend to neutralize them through a relatively easy and quick shortening of the are which would otherwise take place through compression only. The buckling may occur at an early stage of the thrust, giving comparative relief through the remainder of the movement and even through the periods of greatest intensity of movement. Accordingly, a buttress of horizontal competent strata under adequate loading may endure, and undoubtedly has in many cases, more vigorous and long continued differential stresses, and has sustained greater molecular displacement and compacting of the rock, incident to actual compression, than a folded series, even though the thrust may actually have been stronger and covered a greater distance in the latter region. The study of the carbonization in a number of coal fields shows this to be true.

It appears probable that, in regions where the thrusts have been sufficient to cause well loaded strata to form anticlines, the stresses have been great enough to cause the generation of petroleum. If these deductions are well founded, the earlier and minor stresses are connectcd with the production of the heavier oils, anomalous or even inexplicable as this may seem from the chemical standpoint, while the highest grade oils are usually found where the carbonization, resulting from more intense stresses, has approached the limit of oil production.

According to these observations, and contrary to the views of most geologists and chemists, it would appear that the heavy oils, occurring in regions of less thrust and alteration, are the first products of oil generation, while the light oils, occurring in the regions of greater thrust, are the more refined products. Whether the latter are to be regarded as the direct result of the greater compression of organic matter or, perhaps more likely, as oils that have undergone subsequent migration, probably with fractionation by geologic processes, remains to be proved. In this connection, it is to be borne in mind that the solid residues of heavy hydrocarbons, devolatilized in the shales and other strata during the destructive stages beyond the oil limits, are now in evidence as particles of carbon, causing the blackness of slates, some of which were once richly carbonaceous shales, and undoubtedly productive deposits of oil mother substance.

On the other hand, it would appear probable that, in gcneral, oil either is not present or is not segregated in series of sedimentary formations that have never been thrust sufficiently to cause some buckling or undulation under favorable conditions, with the requisite amount of loading. If not sufficiently loaded, they are likely to remain unconsolidated though they may have been folded. In the Coastal Plain formations of the Atlantic States, which appear to be but slightly warped and possibly lack good anticlines and domes, as though the region had been lifted bodily, without local disturbance, on the back of the metamorphic 
basement complex, the apparent absence of oil pools is attributed by some geologists to the lack of folds; this explanation is more likely to be correct than the view that it is due to the absence of sufficient organic matter in the formations. But it is also probable that, over much of the area, the unaltered sedimentary strata have not been thick enough to assure the requisite loading had moderate folding taken place.

In the genesis of an oil pool not only is the organic debris altered and devolatilized, with the generation of petroleum and natural gases, as the result of dynamic thrust stresses attending diastrophic movements, but the migration and segregation of these hydrocarbons, disseminated in their place of origin in the mother rock, are promoted, if not caused, by the molecular rearrangement and the movement of rock grains consequent to these stresses. Most, by far, of the oil and gas is generated under the influence of differential stresses in "impervious" beds, the larger part being formed in the midst of typically impervious deposits, mainly organic muds, carbonaceous clays, fine-grained shales, and dense organic strata, such as oil shales, than which few unaltered sediments can be more impervious. The molecular displacement and the readjustments of the particles of the rock are essential to the migration of the newly formed oil and gas, and of the water, in the directions of least resistance, which, other things being equal, will be toward those beds, or regions of beds, most resistant to pressure and within the pore spaces of which the pressure will be relatively less. Sandy strata, sandstones with grains varying in size and shape, porous limestones, lavas, and, finally, coarse sandstones composed of round grains of uniform size, display varying resistances to compression, with corresponding variation of pore-space pressure. Coalescence of the infinitesimal globules of oil will take place enroute from the yielding to the resistant strata; and as the porous resistant beds with stable grains are traversed, concentration and segregation of the oil, gas, and water will ensue, the water driving the oil and gas into the larger voids by reason of its greater capillary tension, whereby it tends to seize and hold the smaller ones.

The extent to which argillaceous and organic sediments are reduced in volume under pressure is better realized when one recalls that the subsurface layer of a peat bog contains from 80 to 90 per cent. of water, and sub-surface slimes and muds carry nearly as much. At the lignitic (brown coal) stage, the average water contents of the coal bed approaches 38 per cent.; the proportions of water in sub-bituminous, low-rank bituminous, high-rank bituminous, and semi-bituminous coals average $23,15,6$, and 3 per cent. respectively. ${ }^{13}$ To the water losses, a part of which may be attributed to mere loading soon after deposition, are to be added the progressive losses of organic volatile matter, including 
petroleum. The necessity for readjustments of the rock material, as the process goes forward under heavy loading and powerful lateral thrusts, is

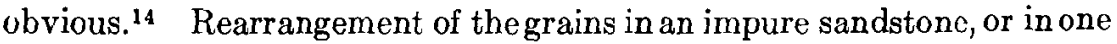
composed of grains varying in size and irregular in shape, will permit less compression than purer coarse sandstone; while a coarse, porous sandstone composed of round grains, if not too rigidly cemented, may even change its shape under lateral thrust without change of volume, until the stresses become so great as to deform the grains, at which stage carbonization will have passed the oil limit. All these conditions tend to drive the oil into the sand having the largest, roundest, and most uniform sized grains.

It may not be out of place here to note that diastrophic movement is not simple or cataclysmic. It is always in progress in one region or another, though its magnitude and vigor are specially noticeable in periods of most marked isostatic adjustment. These periods, though for the most part relatively short, geologically speaking, doubtless span thousands or perhaps hundreds of thousands of years. The complex movement of a lateral thrust may be considered as the product of a cycle, or perhaps a series of cycles of complex differential stresses, possibly cumulative for a period, then decreasing in force, probably to be renewed again and again in greater power, until compression, buckling, or displacement have so far relieved the stresses that they are no longer able to overcome the rigidity and friction of the strata. There is an obvious contrast between those strata which relieve the intensity and continuity of a thrust by buckling, folding, or faulting, and those more competent strata which, though enduring even more intense stresses, are able to relieve them only by horizontal compression.

Plainly, then, during these periods of horizontal diastrophic stresses, the opportunities for progressive readjustment of the particles may have been almost without number. It is reasonable to conclude also that molecular rearrangements have attended these stresses, since the chemical composition of the organic debris and residues has from time to time certainly been altered, with the generation and expulsion of volatile matter, including oil. A study of coals shows an apparently uninterrupted gradation from lignite to anthracite and graphite. It would appear, therefore, that during a period of diastrophic stresses, the conditions have repeatedly been favorable for the evolution of the oil, the displacement and rearrangement of the organic particles and rock grains, the coincident

14 Lateral transfer or flowage, under differential pressures, of the more plastic argillaceous and organic strata in a series of beds varying in composition and thickness is most natural, and is illustrated by the "horses," "squeezes," "ve ning," and "pocketing" of coal and clays, so familiar to the miner in the bituminous, semibituminous and anthracite fields. Such local flowage may cause thin included sandstones or even environing shales to bend in accommodation, thus producing small local anticlines, some of which may be misinterpreted as depositional. 
rupture, enlargement, decrease or rearrangement of the pore spaces and capillaries, the development of zones of varying pressure, the overcoming of friction, and the disorganization of capillary resistance. In short, the conditions must have been most favorable $(a)$ for squeezing oil, gas, and water out of their impervious source, through the intervening, impermeable, organic and argillaceous deposits, into the less compressed regions of the sandy rocks, sandstones, and porous limestones; $(b)$ for their migration in spite of capillary resistance; and $(c)$ for their eventual escape into the most porous, coarse-grained reservoir available, where, under a relative stability of the rock material, segregation and gravitation may be assumed to have taken place, subject to the effect of capillary tension. In some respects, the effects of diastrophic stresses in compressible sedimentary strata may be likened to a jigging of rock particles and mineral grains, in which process existing capillaries may become unstable and disrupted, pore spaces reorganized as to number, form and size, and friction repeatedly overcome; thus the escape, migration, concentration, and segregation of water, oil and gas, into less compressible sandstone and limestone reservoirs were promoted.

Consistent with this interpretation, it would appear that:

1. Oil will be generated only at depths sufficient to assure the necessary loading, which may vary somewhat with the composition and rigidity of the strata and, to some extent, with the intensity of the thrust.

2. In oil fields where the stress has been slight and probably confined to a single period, carbonization (alteration) being in the early stage, the oil is not likely to be found far, stratigraphically, from the carbonaceous sediments. If the thrusts have not been sufficient to drive the water, oil, and gas to a suitable storage "sand," the disseminated oil may not be recoverable. Water, with its stronger capillary tension, will tend to drive the oil into the largest pores available. Accordingly, a lenticular body of open-pored coarse sand may be filled with oil under heavy pressure, independently of anticlinal structure, or even in a shallow structural depression.

3. The largest oil pools normally occur where ample suitable storage is convenient to abundant organic mud or mother substance, unless the thrusts have been too great and carbonization has gone too far. Insufficient storage in very thin or fine-grained sands may be found in extensive carbonaceous formations; for example, the thin sands of the Graneros in the Thornton field, Wyoming, and the fine-grained sands in the Mancos shale in northwestern Colorado and in the Chattanooga shale in Barren County, $\mathrm{Ky}$.

4. The stresses of a diastrophic movement may be sufficient to generate only a part of the oil and gas derivable from the organic mother substance, leaving some to be evolved under later stresses, until oil is no 
longer produced, though gases may continue to be eliminated until the organic substance is wholly devolatilized, leaving only the "fixed carbon."16 From field observations on the progress of devolatilization of organic matter, it is concluded, as already noted, that the first oils are generally heavy, usually with considerable asphalt; the later products, generated in areas of more advanced alteration, are lighter; while the oils from formations and regions where the carbonization limit has been approached are characteristically of the highest grade. This is the reverse of the order in which fractions are obtained by heat distillation.

5. In the course of successive periods of lateral diastrophic stresses, the water, oil, and gas, under cumulative pressures, may be carried through relatively impervious rocks for long distances in the direction of least resistance, if the thrusts and consequent pressures are sufficiently energetic, capillary tension and friction being to some extent counteracted by the forces which cause rearrangement of the rock particles. For this reason, several sands may yield oil generated from a single deposit. Enormous pressures should develop in the lower sands. In fields containing many oil sands, the oil is more likely to be of deep origin.

6. Oil pools generated and localized during one period of stress may be, and probably have been, carried on to new reservoirs, possibly at different horizons, at a later period of greater stress. This may be termed secondary migration and secondary storage. It seems within the limit of probability that some of the oil found in sands stratigraphically remote from recognizably carbonaceous beds may have come from the latter by secondary if not by primary migration. Given sufficient stresses in a great thickness of compressible strata, or pressures sufficient to compress the interlaminated somewhat arenaceous beds, it would seem possible that some of the water, oil, and gas may be forced comparatively near the surface before they are trapped in a sandstone beneath impervious cap-rock; finally, if these sandstones lie sufficiently near the surface to crack, fracture, or buckle under thrust displacement, the oil and gas may even escape from the strata. Consideration must be given to the probable depth of erosion that has occurred in a field, where sands now near the surface are productive.

Whether there is a sort of natural fractionation when the oil pool, at a later period of stresses, is forced into new and perhaps stratigraphically higher reservoirs, cannot now be answered definitely. The facts that (a) the oil disappears eventually in a process of advanced carbonization, leaving only its solid residues as dark carbonaceous matter in the rocks,

${ }^{15}$ This is indicated by the artificial distillation of oil from oil shales in regions which have undergone varying degrees of carbonization, up to the oil limit; only small amounts of oil can be obtained from shales which have been carbonized beyond this limit. 
and that $(b)$ a thin film of oil, including some of the heavier hydrocarbons, is left on the grains around which oil has stood, point toward the improvement of the product with each such transfer. This might account for the progressive refinement of the oils in the course of recurrent periods of thrusting, as mentioned under paragraph 4. The possible depreciation of the oil by percolating surface waters, especially those carrying sulfates, or by escape of the lighter matter to the surface, must not be overlooked.

The problems of secondary migration of oil may be as important as they are interesting, and require further study in both field and laboratory.

The disappearance of oil pools in areas of too advanced carbonization may be due to leakage when jointing and cleavage become more highly developed; or the oil may have been driven to the surface up the dip of the sands; or, as I am inclined to believe, it may have been volatilized, the solid residues remaining in the rock.

Whether it is possible for oil and gas to pass through impermeable clay shales or other cap-rocks except at times of diastrophic readjustment may well be doubted. The extent to which such readjustments are essential to the migration of oil, gas, and water along a stratum so composed, as to size of grains and porosity, as to comprise an oil sand, remains to be experimentally proved; but I am disposed to believe that their migration through "tight" sands and other so-called impervious beds takes place under dynamic stresses of diastrophism.

C. E. Van Orstrand suggests that the geologists of the country may not have given due consideration to the possible influence of osmotic pressure in moving the oil from deeper and warmer strata, in which it originates, to the overlying cooler strata or up the dip into the zones of lower temperature at the apex of an anticline or dome. This subject has been mentioned by Mr. Van Orstrand in the record of his temperature observations in several deep wells of West Virginia and southwestern Pennsylvania. ${ }^{16}$ In this connection, attention is called to a brief discussion, by H. B. Gillette, ${ }^{17}$ of the influence of osmotic pressure in transferring rock solutions from warmer to cooler zones, as relating to the deposition of orebodies.

The oil in the salt domes of the Gulf Coastal Plain may have originated in the strata in which the salt plug is found, or it may have ascended more or less of the distance traversed by the salt. The pressure theory as to the origin of the salt plugs, which seems to demand acceptance,

${ }^{16}$ Discussion of the records of some very deep wells in the Appalachian oil fields of Pennsylvania and West Virginia, by I. C. White, State Geologist, with temperature measurements by C. E. Van Orstrand.

17 Trans. (1903) 34, 710. 
premises local pressures in the surrounding rocks which might be sufficient to cause the generation of such low-grade oils as are usually found in these domes. Oil of higher grade would be expected, in general, at great depth. On the other hand, it has not been proved that the oil did not ascend with the salt, which scems possible. In the latter case the domes may deserve testing to a maximum depth. Proof that the oil was disseminated in the strata, in readiness to migrate horizontally into the monoclines about a dome when the latter was formed, would support the theory that the oil was biochemically formed at the time of deposition of the strata, as suggested by Murray Stuart, ${ }^{18}$ separated by pressure, and segregated gravitationally in the upturned beds surrounding the plug.

\section{Thickness of Sedimentary Formations}

Whether or not the geologist follows my conclusion as to carbonization, and its use as an index of incipient regional alteration, the degree of which approximately determines the limit beyond which productive oil fields will not be found, he must in any case take into account not only the alteration of the sedimentary formations, according to his own conception of the metamorphic limits, but also the thickness of sediments that, according to his judgment, are not too altered, and hence must furnish the oil. However, this subject has awakened less discussion, and therefore less systematic observation, than its very great importance demands.

It will probably be generally agreed that the requisite thickness of sedimentary strata in any oil basin depends on the character, composition, and competence of the strata; the position of the sands and the caprock; the distribution of the mother substance; the structure, the jointing, faulting, erosion, conditions of deposition, etc. Mother substance, reservoir sands, or cap-rock may, of course, be lacking, but for purposes of discussion, it must be assumed that they are all present and favorable, i.e., the organic matter is near but not at the bottom, and the reservoir and cap-rock are next above it. Further, a consideration of the requisite thickness must take into account the probable depth of strata eroded since the oil was generated and brought to its present storage. In other words, the original thickness at the time of deformation by horizontal stresses is to bc regarded, rather than the present thickness in the producing basins, for the original thickness is what determined the amount of load on the organic beds when dynamic action occurred.

A review of the field evidence circumstantially presented by oil fields possessing relatively thin and not too altered strata, lying on a crystalline or thoroughly metamorphosed basement complex, would be both

${ }^{18}$ Records Geol. Survey India (1910) 40, 320-333. 
interesting and valuable, but the data seem insufficient for definite conclusions. I do not recall any oil field, meeting the conditions above mentioned, in which the non-metamorphosed sediments originally aggregated less, in round numbers, than $2000 \mathrm{ft}$. $(600 \mathrm{~m}$.); in most cases the thickness is over $2500 \mathrm{ft}$. $(760 \mathrm{~m}$.). Exceptions should be made of series marginally overlapping on metamorphics, like the Pennsylvanian and Permian on the buried igneous and metamorphic rocks in portions of the Mid-Continent region, where the hydrocarbons may have migrated diagonally through the littoral sands of the relatively steeply transgressive formations.

The question of thickness is possibly of great importance in regions like the Atlantic Coastal Plain, where unaltered and largely unconsolidated sediments lie on pre-Cambrian complexes; also in portions of the Atlantic Trias. As to the Atlantic Coastal Plain, over the greater portion of which the thickness of the Coastal Plain deposits is almost certainly less than $2200 \mathrm{ft}$. ( $670 \mathrm{~m}$.), while throughout large areas it is less than $1200 \mathrm{ft}$. (366 m.), it may be questioned whether, if thrusts sufficient for the generation and migration of oil into coincidentally induced folds had been exerted, the sediments were sufficiently thick to provide enough loading to favor the generation, segregation, and retention of the oil and gas. Almost surely the thickness has been too little, also, over considerable areas in those marginal zones of the Coastal Plain formations in the Gulf embayment, where the Cretaceous and Tertiary sediments lie on metamorphic or crystalline series.

On the other hand, the presence of oil in relatively thin sediments overlying other sedimentary formations, in which the carbonization has not gone far beyond the limit cited above, may not be precluded, in accordance with the suggested migration of hydrocarbons during recurrent periods of thrust stresses. The Madill, Okla., field seems to offer an illustration. The stresses inducing incipient metamorphism in an unconformably overlying formation must further alter the lower formation, which may already have nearly reached the carbonization limit. However, the presence of oil pools in thin unaltered sediments, where the alteration of the carbonaceous debris in underlying formations has progressed considerably past the carbonization limit-say, into the semi-bituminous (fuel ratio 3.0 or more) or the semi-anthracite rankwould be very interesting and worthy of record. In such an occurrence, the questions will be: Did the oil (a) originate in the lower series and pass into the younger by primary or secondary migration, as seems most probable; $(b)$ condense from vapors generated in the lower series during the progressive alteration after the upper sediments were laid down; or (c) originate in the upper series?

The evidence bearing on these questions is not sufficiently complete and coördinated to encourage a satisfactory discussion at this time, due voL. $2 \times x,-13$. 
largely to the lack of observation on carbonization and other indices of incipient metamorphism of the sediments, including the carbonaceous deposits. Factors to be considered in this connection include unconformities at erosional intervals, as affecting the escape or deterioration of oils near the old erosion surfaces; migration of oil and gas up the dips to the margins of transgressing formations or through littoral zones to higher formations; thicknesses of rock eroded from producing formations; and the effects of sealing on oil pools in the sands. The application of the problem to many regions is obvious.

\section{Conditions of Deposition}

Aside from such facts as the presence of adequate organic matter, of sands suitably composed and situated for service as oil reservoirs, of cap-rocks properly located, etc., some of which have already been mentioned, a question which should not be ignored in the search for oil in a new region, such, for example, as the Tertiary freshwater basins of eastern Washington and Oregon, or in the Great Basin region, is whether or not the beds concerned in the generation and storage of the oil are strictly of freshwater origin, and particularly whether the oil-bearing series was laid down in an exclusively non-marine basin. Inseparably connected with this question is the related one as to the importance of the association of salt water or gypsum in the oil-producing formations, as is so insistently urged by some geologists, with citation of circumstantial evidence. On these matters opinion differs widely, possibly without succinct data sufficient for a final decision.

As criteria to be considered in the answering of this problem the following may be noted:

(1) Ample organic matter undoubtedly suitable for the generation of oil and gas was deposited with the sediments in many of the freshwater basins. These deposits contain oil shale of high quality, which, on distillation, yields oil essentially like and possibly indistinguishable from that obtained from oil shales of marine origin. Many of the organic products are common to both habitats.

(2) The mechanical constitution of the deposit in both marine and freshwater formations is essentially the same.

(3) Important oil-bearing sands and organic remains were deposited during intervals, sometimes of considerable length, during which only freshwater sediments were laid down, these deposits being intercalated in brackish water or marine sediments.

(4) Oil-bearing sands and organic deposits were laid down in waters, but slightly saline, in the younger formations of the Appalachian trough.

(5) Some salts are present in freshwater deposits.

(6) Natural gas is present in freshwater basins, and has been developed at considerable depth in such basins. 
(7) While it may be true that, in the geologic processes of oil generation, salt in amounts premising marine or brackish water deposition may be essential as a catalyzer or otherwise, the fact remains to be demonstrated, possibly in the laboratory. The absence of salt does not appear to affect the artificial production of oil by distillation of shale.

It is possible that in some of our oil fields, salt water may have found its way downward through joints or along the dip into frosh-water beds subsequently submerged beneath the sea, somewhat like the invasion of fresh water down the dips of some of the marine oil sands in California. On the other hand, fresh-water basins in which the requisite conditions as to depth, organic matter, sands, cap-rocks, thrusting, and incipient alteration favorable for oil pools are fulfilled, and which have never subsequently been submerged beneath the sea, have been too little tested to justify conclusions as to their possibilitios for oil production. Such basins, if actually closed and without outlet, will be more or less distinctly alkaline. At the present stage of our knowledge, fresh-water basins appearing otherwise to meet the requirements should be wildcatted without prejudice.

\section{DISCUSSION}

R. H. Johnson, Pittsburgh, Pa.-It seems to me that the case for the fresh-water origin of natural gas must be accepted, since the coal progressively loses methane. We know that much natural gas must have arisen in that way. My reserve in connection with petroleum in contrast with natural gas.comes from the fact that if the fresh-water deposits have been as productive of petroleum as the marine, the field evidence ought to show us more petroleum in close proximity to the coal; it is this that leaves me skeptical as to very much fresh-water petroleum, although we must admit a great deal of fresh-water natural gas.

H. W. Hrxon, New York, N. Y.-In the Appalachian field, how much oil and gas do you find above the coal? I am not well informed on that subject, but I have not heard of a case where oil and gas occurred above the coal in Pennsylvania or West Virginia, except possibly that which had migrated there along a fault. There is another thing, you cannot saponify petroleum and you cannot make glycerine out of petroleum. If you could do that, why should we have paid such high prices for glycerine during the war? You can saponify organic oil and you can make glycerine out of animal fats, so that the petroleum and animal fats differ entirely. Also, petroleum has no food value.

We differ fundamentally as to our ideas about the origin of petroleum and natural gas, and I think we will have to let it go at that. As regards the origin of the force, the dynamic force, that causes these deformations, the elevation and folding, I consider that these gentlemen 
are laboring under the impression that it is contraction. I have studied that question for a number of years and find that the best authorities on the subject state that the total amount of contraction of the interior of the earth, due to loss of temperature, in $100,000,000$ years would prove a circumferential contraction of about 7 miles, and that if all of the folding and faulting and overthrust of the various mountain ranges of the earth were ironed out, they would amount to something like 150 to 200 miles. There is a decided difference that has to be accounted for. I account for it in an entirely different way; that the gases which cause elevation by reduction of density, as the surface of a loaf of bread is raised by reduction of density, tend to accumulate and migrate toward the axis of elevation. They carry the crust in two directions and, because of the reduced density, creep toward the axis of elevation or toward the center of the dome. The hydrocarbons are in the gaseous interior of the earth for exactly the same reasons as all the other gases-because of the diffusion of gases in the original gaseous planet in that gaseous core, and they have remained there ever since, being held by the power of diffusion. The change from the gaseous to the solid condition is by loss of temperature. It then becomes lighter at the same time, because the gaseous core must be denser than the solids that lie upon it.

My contention is that petroleum, natural gas, and the helium with them are of voleanic origin. The origin of oil and gas is connected with the whole theory of earth physics, which is entirely different from the old contraction hypothesis, on which most of the geologists base their theory of mountain formation.

The authorities on the subject state that the earth's crust, considered as a dome, is not capable of supporting one five-hundredth part of its own weight. If it is not capable of supporting any more than that portion of its own weight, it must be supported by the material below it at all times, whether it is above sea level or below sea level. We find rocks of marine origin in the highest mountains. They did not get there by accident; and if they were supported by the material below them at all times, and they are above sea level at one time and below sea level at a previous time, the only possible solution of that problem is that the matter below the zone of fracture has varied in density between those two periods. So that you come to a question of accounting for that variation in density between two geological periods; that, I maintain, is due to the accumulation of magmatic gases derived from the gaseous core denser than the solids which will form out of it when cold.

DAvid REGER, * Morgantown, W. Va.--Regarding the statement just made that oil has not been found above the coals in the Appalachian Basin, I would like to say that one of the first wells in the West Virginia

* Assistant Geologist, West Virginia Geol. Survcy. 
fields was about $300 \mathrm{ft}$. deep, at Burning Springs on the Little Kanawha River in 1860 . When I visited the well in 1909,49 years after its completion, it was still producing $30 \mathrm{bbl}$. of oil a month and 10 years later, in 1919, was still producing. Only the owner knows how many thousands of barrels the well has actually produced in that time. The producing formation there was the Cow Run sand, which is right in the middle of the Coal Measures. This well is on the Burning Springs which extends half way across the state. The great producing sands have been the two Cow Runs, which have coal measures above and below them. It is my opinion that while the first oil in the state was found in the coal measures, it is entirely possible that the last drilling and the last production of oil to be eventually found in the state will be in the same coal measures.

H. W. Hrxon. - I believe I stated that if the oil or gas migrated to that particular place along a fault it might be found there, but it all comes from below the coal.

\section{DAVID REGER.--There is no fault there.}

J. F. Duce, Denver, Colo. (written discussion).-The question of the presence of carbonaccous material in the "Red Beds," is an old one. The Triassic "Red Beds" of New Mexico are certainly carbonaceous and at times bituminous. Certain of the sandstones are crowded with fossil wood, while directly above these will be found bituminous sands. This is true also in the Dockum of Texas. Of the underlying strata in northern New Mexico we cannot be so certain, as they are largely arkoses. The basal members of the Manzano group contain some limestones, but M. G. Girty states that the fossils are not well preserved, which suggests erosion on the sea floor before entombment.

In the southern part of New Mexico, the occurrence of the limestones and bituminous shales of the Guadalupe Group at the base of the Triassic and the great thickness of limestones in the Manzano (Hueco) suggests the presence of petroleum; these same rocks are probably the source of the oil in the ariesian wells of the Roswell area.

It is perhaps well to bear in mind that the criterion that White suggests concerning the state of metamorphism of the coals in an area is applicable but locally in the Rocky Mountains. We are confronted there with exceedingly rapid structural changes, and it is along the axes of these changes that the coal fields White has mentioned occur. Recent investigations by Richardson, Lee, and Ziegler have changed our conception of Rocky Mountain structure. The steep monoclines that form the mountain front die out abruptly both east and west, and seem in some cases to have been accompanied by strike faults. The zone of intense folding is therefore narrow and is frequently associated with 
volcanic activity. Along the flanks of these sharp folds most of the producing Rocky Mountain coal fields are grouped; here, too, there is the maximum metamorphic effect, so that the coals are of high grade. $\Lambda$ s we pass from the folding, the coal becomes poorer and poorer. The coals in the Trinidad field are associated with the intrusives of the Spanish Peaks group, the coals of the Durango field with the intrusives of the San Juan group, the coals of Crested Butte with the Crested Butte intrusives, and those of the Anthracite Range with the Elkhead Mountain intrusives. This connection is surely not accidental. In one case, however, at New Castle, the high-grade coals are not associated with eruptives but with sharp folding alone. (Basalt flows are present in the near vicinity but I am speaking here of intrusives). If now we pass from the focus of folding and igneous activity but a short distance, the grade of the coal changes markedly, and in accordance with White's theory. We must, therefore, restrict this criterion of the fuel ratio of the associated coals to the locality in which the coals occur and cannot extend it generally to formations beyond the field in which the high fuel ratio coals occur. Further than this, if petroleum migrates up the flank of Rocky Mountain monocline, we would expect even within the metamorphic areas petroleum that had migrated from farther down the slope where unmetamorphosed sediments occur, unless the metamorphism has reached a point where the porosity of the strata through which it must migrate has been affected. Lighter oils would, however, be expected, as the long journey would result in the fractionation of the original oil.

In connection with the origin of petroleum, it is interesting to note that almost all the Cretaceous oil of Wyoming is produced from the lower Colorado group, and that the oil sands are directly associated with the bituminous shales of the Mowry and equivalent formations. 